\title{
Saccharomyces cerevisiae CAMP-dependent protein kinase controls entry into stationary phase through the Rim15p protein kinase
}

\author{
Anke Reinders, Niels Bürckert, Thomas Boller, Andres Wiemken, and Claudio De Virgilio' \\ Botanisches Institut der Universität, $\mathrm{CH}-4056$ Basel, Switzerland
}

\begin{abstract}
The Saccharomyces cerevisiae protein kinase Rim15p was identified previously as a stimulator of meiotic gene expression. Here, we show that loss of Rim15p causes an additional pleiotropic phenotype in cells grown to stationary phase on rich medium; this phenotype includes defects in trehal ose and gycogen accumulation, in transcriptional derepression of H SP12, HSP26, and SSA 3, in induction of thermotolerance and starvation resistance, and in proper $G_{1}$ arrest. These phenotypes are commonly associated with hyperactivity of the Ras/CAMP pathway. Tests of epistasis suggest that Rim15p may act in this pathway downstream of the CAMP-dependent protein kinase (CAPK). Accordingly, deletion of RIM 15 suppresses the growth defect of a temperature-sensitive adenylate-cyclase mutant and, most importantly, renders cells independent of cAPK activity. Conversely, overexpression of RIM 15 suppresses phenotypes associated with a mutation in the regulatory subunit of CAPK, exacerbates the growth defect of strains compromised for CAPK activity, and partially induces a starvation response in logarithmically growing wild-type cells. Biochemical analyses reveal that CAPK-mediated in vitro phosphorylation of Rim15p strongly inhibits its kinase activity. Taken together, these results place Rim15p immediately downstream and under negative control of cAPK and define a positive regulatory role of Rim15p for entry into both meiosis and stationary phase.
\end{abstract}

[Key Words: Rim15p; protein kinase A; yeast; Ras; CAMP; nutrient signaling]

Received April 27, 1998; revised version accepted July 10, 1998.

The CAM P-dependent protein kinase (CAPK) pathway in the yeast Saccharomyces cerevisiae is required for proper regulation of growth, cell cycle progression, and development in response to nutritional conditions. Cells deficient in CAPK activity stop growth, arrest in $\mathrm{G}_{1}$, and show physiological changes normally associated with nutrient deprivation; these changes include the accumuIation of trehalose and glycogen, enhanced expression of various genes (e.g., SSA 3, HSP12, HSP26, CTT1, U BI4, and $A D H 2$ ), and increased resistance to heat stress. In contrast, cells carrying mutations that yield elevated CAPK activity fail to arrest in $\mathrm{G}_{1}$, are defective for trehal ose and glycogen accumul ati on, rapi dl y l ose viability, and remain highly sensitive to heat stress upon nutrient starvation (for review, see Tatchell 1986; Thevelein 1994). On the basis of these results, it was suggested that the central role of the yeast CAPK pathway is in signaling the nutrient status, thereby participating in the cell's decision to enter a quiescent state in $G_{1}$ that is equivalent to the $\mathrm{G}_{\mathrm{o}}$ state of higher eukaryotes. Accordingly, Iow levels of CAPK activity promote exit from the mi-

${ }^{1}$ Corresponding author.

E-MAIL devirgilioc@ubaclu.unibas.ch; FAX 41612672330 totic cell cycle and entry into $G_{0}$, while high levels of cAPK activity preclude access to $\mathrm{G}_{0}$.

The activity of $\mathrm{S}$. cerevisiae CAPK is regulated by a complex signaling pathway that includes two yeast homologs of mammalian ras proteins. The yeast RAS1 and RAS2 gene products (Ras) are small GTP-binding proteins that are activated by a GTP-exchange factor (GEF; encoded by CDC25) and inactivated by stimulation of the intrinsic GTPase-activity via GTPase-activating proteins (GAP; encoded by IRA 1 and IRA 2). Activated GTPbound Ras stimulates adenylate cyclase (encoded by CYR1/CDC 35) to yield increased levels of CAMP that can be degraded by the low- and high-affinity phosphodiesterases encoded by the PDE1 and PDE2 genes, respectively. Binding of CAMP to the regulatory subunits of CAPK (encoded by BCY1) results in their dissociation from the catalytic subunits (encoded by three functionally redundant genes, TPK 1 , TPK 2 , and TPK3) and in stimulation of CAPK activity (for review and further details on the Ras/cAMP pathway, see Tatchell 1986; Gibbs and Marshall 1989; Broach and Deschenes 1990; Thevelein 1994). While the components of the Ras/ CAM P pathway required for activation of CAPK are well established, little is known about the mechanisms of 
activation of the pathway by biological signals (i.e., nutrients) or about the potential biochemical targets of CAPK. These include enzymes involved in carbohydrate and phospholipid metabolism and various regulators of transcription, as well as proteins involved in synthesis and degradation of CAMP. Many of these potential targets, however, have not been unequivocally shown to be directly phosphorylated by CAPK, and it is likely that CAPK impinges on some of these targets rather indi rectly (for review, see Broach and Deschenes 1990).

A fairly well established example of direct regulation by CAPK-catalyzed phosphorylation, by means of genetic, physiological, and biochemical analyses, is provided by the trehalose degrading enzyme trehal ase (for review, see Thevelein 1996). Accumulation of the nonreducing disaccharide trehal ose is an element of the adaptive response of yeast cells to nutrient starvation (Lillie and Pringle 1980). In general, resumption and stimulation of growth upon readdition of nutrients to starved cells are associated with mobilization of trehalose by rapid CAPK-dependent activation of neutral trehal ase. Interestingly, it was suggested that not only the neutral trehalase but also the second key enzyme of trehalose metabolism, namely the trehalose-6-phosphate (T re6P) synthase, may be regulated by CAPK-catalyzed phosphorylation (Panek et al. 1987). Accordingly, trehalose levels may be finely tuned in response to the nutritional status by reciprocal regulation (i.e., activation of neutral trehalase and inactivation of Tre6P synthase) via CAPKmediated phosphorylation of the key enzymes of trehalose metabolism. However, al though control of neutral trehalase by CAPK-dependent phosphorylation seems well established, there has been controversy as to whether Tre6P synthase is al so regulated by CAPK-cataIyzed phosphorylation (Vandercammen et al. 1989).

Tre6P synthase itself is part of a multimeric protein complex that is composed of at least four different subunits encoded by the genes TPS1, TPS2, TPS3, and TSL1. Recent studies indi cated that Tps1p and T ps $2 p$ carry the catalytic activities of Tre6P synthase and Tre6P phosphatase, respectively, whereas Tps3p and Tsl $1 p$ were suggested to have regulatory and/or structural functions (Bell et al. 1992; De Virgilio et al. 1993; Vuorio et al. 1993; Reinders et al. 1997). A particularly surprising aspect of studies of the Tre6P synthase/ phosphatase complex in S. cerevisiae was the finding that tpsl mutants (including various allelic mutants) are defective not only for Tre6P synthesis but also for growth on glucose, apparently because of an uncontrolled influx of glucose into the glycolytic pathway. Therefore, it has been suggested that T pslp may be involved in the control of glycolysis (for review, see Thevelein and Hohmann 1995; and references therein).

In view of this newly discovered role of Tpslp in regulation of the glycolytic pathway and its own possible regulation via the Ras/CAMP signaling pathway, identification of proteins that can interact with Tpslp may reveal novel regulatory mechanisms of both glucose influx and/or signal transduction via the Ras/cAMP pathway. To isolate such potential regulatory proteins, we undertook a two-hybrid screen for proteins that interact with Tpslp. Here, we describe the identification of the Rim15p protein kinase, previously identified as a stimulator of meiotic gene expression (Vidan and Mitchell 1997), as a Tpslp-interacting protein. Deletion of RIM 15 results in a defective response of mutant cells to nutrient limitation, including a defect in trehal ose accumulation, that is reminiscent of the effects caused by mutations that constitutively activate CAPK (e.g., bcyl and RAS2 ${ }^{\text {Val19}}$ ). Tests of epistasis as well as biochemical studies suggest that Rim15p acts immediately downstream of CAPK to control a broad range of physiological adaptations necessary for proper entry into stationary phase.

\section{Results}

Cloning and sequence analysis of RIM 15

To identify previously uncharacterized genes whose products interact with the Tre6P synthase (T pslp) of S. cerevisiae, we performed a two-hybrid screen (Fiel ds and Sternglanz 1994; Zervos et al. 1993; see Materials and Methods). We rescued library plasmids from cells (EGY48; Table 1) in which both reporter genes showed gal actose-dependent transcription and assigned the plasmids to three different classes by restriction mapping. Partial sequencing of plasmids of one class showed them to contain a previously unidentified gene with high homology to protein kinases. We decided to first study this gene and named it TAK1 (for Tpslp-associated protein kinase). During the course of our studies, however, the same gene was identified as RIM15 in an independent screen for mutations that cause reduced expression of IME2 (Vidan and Mitchell 1997). In addition, the TAK1/ RIM15 sequence is identical to the open reading frame YFL033C identified as part of the Yeast Genome Sequencing Project (M urakami et al . 1995). We will refer to this gene and its product as RIM 15 and Rim15p, respectively. In accordance with Vidan and Mitchell (1997), we found RIM 15 to specify a 1770-residue pol ypepti de comprising a domain with high homology to serine/threonine protein kinases of the protein kinase $C$ and protein kinase A subfamilies (see al so Hunter and Plowman 1997). A notable feature of the predicted Rim15p amino acid sequence is the presence of five consensus sites for CAPK phosphorylation, Arg Arg X Ser (Edel man et al. 1987).

Analysis of the nine RIM15 library plasmids isolated in the two-hybrid screen revealed that they all contained the same fragment of RIM15, corresponding to amino acids 761-1051 of the predicted full-length gene product. As shown in Table 2, this Rim15p $p_{761-1051}$-activation domain fusion (AD) interacted with the Tpslp-DN A-binding domain fusion (DBD), but not with Tps2p-DBD, Tps3p-DBD, or Tsl1p-DBD. Because all four predicted proteins, Tps1p, Tps2p, Tps3p, and Tsl 1p, share high homology over the entire length of the Tpslp sequence, these two-hybrid data indicate that the observed interaction between Rim15p $p_{761-1051}-A D$ and Tpslp-DBD is highly specific. 
Table 1. List of yeast strains

\begin{tabular}{|c|c|c|c|}
\hline Strain & Genotype & & Source \\
\hline YEF473 & $\mathrm{MATa} / \alpha$ & his3/his3 leu2/leu2 Iys2/lys2 trp1/trp1 ura3/ura3 & Bi and Pringle (1996) \\
\hline AR1 & $\mathrm{MATa} / \alpha$ & $\begin{array}{l}\text { his3/his3 leu2/leu2 lys2/lys2 trp1/trp1 ura3/ura3 } \\
\text { rim15s::kanMX2/RIM15 }\end{array}$ & this study \\
\hline AR1-1B & $\operatorname{MAT} \alpha$ & his3 leu2 lys2 trp1 ura3 rim15s::kanMX2 & segregant from AR 1 \\
\hline AR1-1C & MATa & his3 leu2 lys2 trp1 ura3 rim15s::kanMX2 & segregant from AR 1 \\
\hline AR2 & $\mathrm{MATa} / \alpha$ & $\begin{array}{l}\text { his3/his3 leu2/leu2 lys2/lys2 trp1/trp1 ura3/ura3 } \\
\text { rim15s::kanMX2/rim15s::kanMX2 }\end{array}$ & AR1-1B X AR1-1C \\
\hline SP1 & MATa & ade8 his3 leu2 trp1 ura3 & Toda et al. (1985) \\
\hline T16-11A & MATa & his3 leu2 trp1 ura3 bcy1-1 & Toda et al. (1985) \\
\hline PD 6517 & MAT $\alpha$ & ade8 leu2 trp1 cdc35-10 & Becher dos Passos et al. (1992) \\
\hline N B11 & MAT $\alpha$ & ade8 leu2 trp1 cdc35-10 rim15s::kanMX2 & this study \\
\hline S7-7A $\times S 7-5 A$ & $\mathrm{MAT} \mathbf{a} / \alpha$ & $\begin{array}{l}\text { ade8/ade8 his3/his3 leu2/leu2 trp1/trp1 ura3/ura3 } \\
\text { TPK1/tpk1::U RA3 TPK2/tpk2::HIS3 } \\
\text { TPK3/tpk3::TRP1 }\end{array}$ & Toda et al. (1987) \\
\hline N B13 & $\mathrm{MAT} \mathbf{a} / \alpha$ & $\begin{array}{l}\text { ade8/ade8 his3/his3 leu2/leu2 trp1/trp1 ura3/ura3 } \\
\text { TPK1/tpk1::U RA3 TPK2/tpk2::HIS3 } \\
\text { TPK3/tpk3::TRP1 RIM15/rim15s::kanMX2 }\end{array}$ & this study \\
\hline NB13-1D & $\operatorname{MAT} \alpha$ & $\begin{array}{l}\text { ade8 his3 leu2 trp1 ura3 tpk2::HIS3 tpk3::TRP1 } \\
\text { rim15s::kanMX2 }\end{array}$ & segregant from NB13 \\
\hline NB13-14D & MATa & $\begin{array}{l}\text { ade8 his3 leu2 trp1 ura3 tpk1::U RA3 tpk2::HIS3 } \\
\text { tpk3::TRP1 rim15s::kanMX2 }\end{array}$ & segregant from N B13 \\
\hline EGY 48 & MAT $\alpha$ & his3 trp1 ura3 LEU 2::pLexAop6-LEU 2 & Zervos et al. (1993) \\
\hline
\end{tabular}

RIM 15 is required for proper entry into stationary phase

To determine the consequences of the loss of Rim15p, we replaced the complete RIM15 coding region by a PCR-based gene deletion method using the kanMX2 module (Wach et al. 1994; see Materials and Methods). The heterozygous RIM15/rim15s diploid AR1 was sporulated and the deletion was shown to segregate 2:2 as judged by geneticin resistance of the resulting colonies. Two tetrads were checked by PCR and Southern blotting, and, in each case, the presence of the sel ectable marker correlated with the shift in fragment size expected for the deleted alleles (data not shown). Thus, RIM 15 is not essential for growth or germination.

For further analysis of the effects of rim15 15 we constructed a homozygous diploid rim $15 \Delta /$ rim15 $\Delta$ strain (AR2) by mating an appropriate pair of geneticin-resistant segregants of AR1 (Table 1). The rim15 $\Delta /$ rim15 $\Delta$ strain had no obvious growth defect at $30^{\circ} \mathrm{C}$ or $37^{\circ} \mathrm{C}$ on all carbon sources we tested, including glucose, fructose, sucrose, raffinose, maltose, glycerol, and ethanol (data not shown). Because our two-hybrid analyses suggested that Rim15p may interact with Tpslp, we assayed the rim $15 \Delta /$ rim $15 \Delta$ strain for its capacity to accumulate trehal ose during a mild heat shock and in stationary phase. Although the rim $15 \Delta /$ rim $15 \Delta$ mutant accumulated wild-type levels of trehalose during a 1-hr heat shock at $42^{\circ} \mathrm{C}$ (i.e., $0.345 \pm 0.033$ and $0.377 \pm 0.009 \mathrm{gram} / \mathrm{gram}$ protein for the rim $15 \Delta /$ rim $15 \Delta$ mutant and the isogenic wild type, respectively), it was found to contain very low amounts of trehal ose in stationary phase when compared with the isogenic wild type (Table 3). Surprisingly, this deficiency in stationary phase-induced trehalose accumulation was not reflected in any detectable changes in the activities of the two key enzymes of trehalose metabolism, namely Tre6P synthase and neutral trehalase.

As the rim $15 \Delta /$ rim $15 \Delta$ mutant was found to be defective for trehalose synthesis upon entry into stationary phase, we al so determined a variety of other phenotypic traits characteristic of stationary phase cells (WernerWashburne et al. 1993). The rim $15 \Delta /$ rim $15 \Delta$ mutant was found to be normal for derepression of invertase (Table 3). However, it was impai red in its ability to accumulate glycogen, to induce SSA 3 transcription (as measured by induction of an SSA3-lacZ fusion gene), to acquire thermotolerance, and to arrest properly in $\mathrm{G}_{1}$ (as measured by the percentage of budded cells) upon entry into stationary phase (Table 3 ). As a result, the strain was al so highly sensitive to prolonged starvation (e.g., 10 days in

Table 2. Two-hybrid interactions between Rim15p and the subunits of the trehalose-6-phosphate synthase complex in Saccharomyces cerevisiae

\begin{tabular}{lcccc}
\hline \multirow{2}{*}{ AD fusion } & \multicolumn{4}{c}{ DBD fusions } \\
\cline { 2 - 5 } & TPS1 & TPS2 & TPS3 & TSL1 \\
\hline RIM15-P & $46.8 \pm 12.4$ & $6.0 \pm 4.0$ & $1.3 \pm 0.6$ & $2.4 \pm 1.0$ \\
pJG4-5 & $2.0 \pm 1.4$ & $1.1 \pm 0.3$ & $3.1 \pm 2.5$ & $2.3 \pm 1.4$ \\
\hline
\end{tabular}

Possible interactions between Rim15p and Tps1p, Tps2p, Tps3p, or Tsl 1p were detected using the two-hybrid system as described in $\mathrm{M}$ aterials and M ethods. N umbers represent mean $\beta$-gal actosidase activites (in Miller units) \pm S.D.s from three independent transformants for each pair of plasmids. pJG4-5 indicates the $A D$ vector without insert. Note that the Tps1p-DBD, Tps2pDBD, Tps3p-DBD, and Tsl 1p-DBD fusions were all shown previously to interact with a Tpslp-AD fusion (Reinders et al. 1997). RIM 15-P codes for an internal part of Rim15p comprising a section of the kinase domain (amino acids 761-1051). 
Table 3. Effects of RIM 15 deletion

\begin{tabular}{|c|c|c|c|c|}
\hline & \multicolumn{2}{|c|}{ RIM15/RIM15a } & \multicolumn{2}{|c|}{$\operatorname{rim} 15 \Delta / \operatorname{rim} 15 \Delta^{a}$} \\
\hline & $\log$ & stat & $\log$ & stat \\
\hline \multicolumn{5}{|l|}{ Enzymes and metabolites } \\
\hline Tre6P synthase ( $\mu$ mole/sec per gram protein) & 0.33 & 1.32 & 0.37 & 1.17 \\
\hline trehalase ( $\mu$ mole/sec per gram protein) & 0.09 & 0.17 & 0.05 & 0.16 \\
\hline invertase ( $\mu \mathrm{mole}$ /sec per gram protein) & 2.00 & 12.93 & 1.93 & 12.06 \\
\hline SSA3-lacZ induction ${ }^{\mathrm{b}}$ (Miller units) & 4.30 & 105.20 & 2.40 & 16.30 \\
\hline trehal ose (gram/gram protein) & $\varangle 0.001$ & 0.199 & $\lessdot 0.001$ & 0.009 \\
\hline glycogen (mg/gram protein) & 1.63 & 38.53 & 0.93 & 11.36 \\
\hline Thermotolerance ${ }^{\mathrm{c}}(\%$ survival) & 0.13 & 35.60 & 0.07 & 0.03 \\
\hline Stationary phase survivald $(\%)$ & & 100.00 & & 20.20 \\
\hline Budded cells ${ }^{e}(\%)$ & 65.70 & 0.90 & 65.70 & 24.30 \\
\hline
\end{tabular}

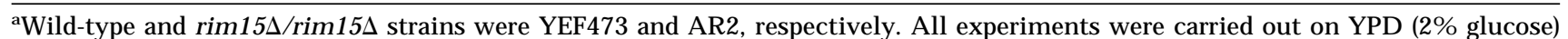
medium using either log phase (log) or 4-day-old stationary phase (stat) cells, except where otherwise stated. Values represent means of at least three independent experiments; S.D.S were, in each case, $<10 \%$ of the corresponding means.

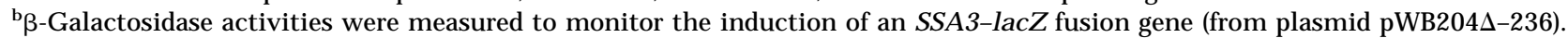

'Thermotolerance was measured as the percent survival following a heat shock for $8 \mathrm{~min}$ at $50^{\circ} \mathrm{C}$ (log-phase cells) or $20 \mathrm{~min}$ at $53^{\circ} \mathrm{C}$ (stationary-phase cells).

'T he percentage of viable cells was determined by the col ony-forming efficiency on Y PD agar of 10-day-old stationary-phase cultures. eThe percentage of budded cells was determined by microscopic examination of at least 200 cells.

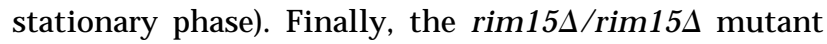
also exhibited much lower sporulation efficiency $(0.6 \% \pm 0.5)$ than the wild type $(31.1 \% \pm 5.6)$. Thus, the RIM15 gene is required for sporulation and for proper entry into stationary phase.

The observed pleiotropic response to nutrient limitation and the defect in sporulation caused by deletion of RIM15 are reminiscent of the effects of two previously described mutations in the Ras/cAMP pathway, namely RAS2 ${ }^{\text {Val } 19}$ and bcy1, which both result in uncontrolled activation of CAPK (Kataoka et al. 1984; Cannon and Tatchell 1987; Toda et al. 1987). Thus, Rim15p might be involved in signaling the status of nutrient supply (or limitation) at some point in the Ras/CAMP pathway. Therefore, we analyzed the transcription patterns in wild-type and rim15 15 rim15 cells of various genes (including SSA3, HSP12, U BI4, and ADH2) that are known to be under negative control of CAPK activity (T anaka et al. 1988; Cherry et al. 1989; Boorstein and Craig 1990; Varela et al. 1995). A comparison of transcript level s during exponential phase, diauxic shift, post-diauxic shift, and stationary phase in wild-type and rim15 $15 /$ rim15 cells is shown in Figure 1. Although the wild-type strain showed the expected pattern of transcriptional repression during exponential growth and transcriptional derepression after the diauxic shift for all five of these genes, the rim $15 \Delta /$ rim $15 \Delta$ strain was seriously defective for transcriptional derepression after the diauxic shift of SSA3, HSP12, and HSP26, but not for derepression of $\mathrm{UBI} 4$ and ADH2. In fact, derepression of ADH2, the only gene of this group whose expression is known to be controlled by CAPK-dependent inactivation of the transcriptional activator Adrlp (Cherry et al. 1989), was even found to be enhanced during the post-diauxic phase and in stationary phase. We also examined the expression pattern of the cold-inducible SSB1 gene, a member of the Hsp70p subfamily, whose transcription is repressed upon entry into stationary phase (Werner-Washburne et al. 1989). No significant difference in the SSB1 repression pattern in wild-type and rim15 1 /rim15 $\Delta$ cells during and after the diauxic shift was found (Fig. 1). Taken together, these results indicate that Rim15p is required for the stationary phase-induced transcriptional derepression (or activation) of a subset of genes (SSA3, HSP12, and HSP26) known to be negatively controlled by cAPK. In accordance with such a role of Rim15p, expression of RIM15 itself was found to be very weak during exponential growth but to be highly induced during the diauxic shift and the subsequent post-diauxic and stationary phases (Fig. 1).
RMTSRWAS

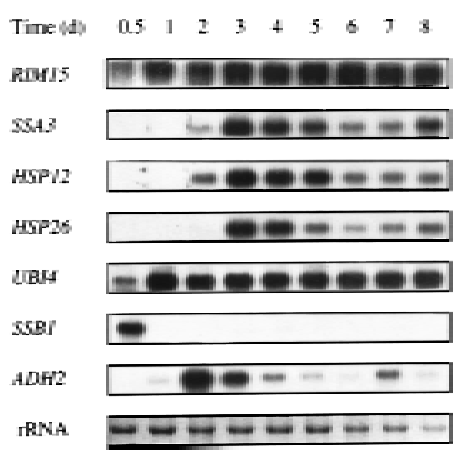

nivisum $15 \mathrm{~s}$

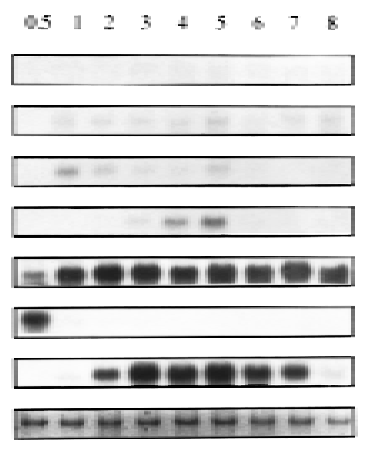

Figure 1. Abundance of various mRNA species as wild-type

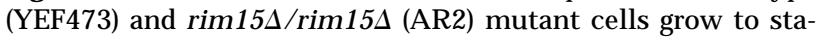
tionary phase in YPD medium. Total RN As extracted from cells in exponential phase ( 0.5 day), diauxic shift phase ( 1 day), postdiauxic shift phase ( 2 and 3 days), and stationary phase (4-8 days) were extracted at the times indicated and equal amounts $(10 \mu \mathrm{g})$ were probed with RIM 15, SSA 3, HSP12, HSP26, UBI4, SSB1, and ADH2 fragments after el ectrophoresis and blotting. The application and transfer of equal amounts of RNA were verified by ethidium bromide staining. 
Loss of Rim15p suppresses cdc35ts and total loss of CAPK

To elucidate whether Rim15p may act in the Ras/cAMP pathway, we determined whether the loss of Rim15p could suppress the conditional growth of a temperaturesensitive adenylate cyclase mutant. To this end, the rim15::kanMX2 deletion was introduced into strain PD 6517 (cdc35-10), and three geneticin-resistant colonies were tested for growth at the non-permissive temperature of $35^{\circ} \mathrm{C}$. In all cases, deletion of RIM 15 was found to allow growth at this temperature. Thus, cdc3510 (PD 6517) and cdc35-10 rim15 (N B11) cultures had an $\mathrm{OD}_{600}$ of $0.15 \pm 0.06$ and $4.47 \pm 0.26$, respectively, after inoculation $\left(O D_{600} 0.05\right)$ and growth for 2 days at $35^{\circ} \mathrm{C}$ in liquid YPD ( $2 \%$ glucose) medium.

To examine whether Rim15p may function immediately downstream of Cdc35p or at a later step in the Ras/cAMP pathway, we tested whether deletion of RIM15 could suppress the complete loss of CAPK. To this end, a heterozygous TPK1/tpk1 TPK2/tpk2 TPK3/ tpk3 diploid strain (S7-7A $\times$ S7-5A) was transformed to geneticin-resistance with the rim15::kanMX2 deletion construct and allowed to sporulate, and the asci were dissected on YPD agar. As expected tpk1 tpk2 tpk3 RIM15 spores failed to germinate (as judged by segregation of the auxotrophic markers). However, tpk1 tpk2 tpk3 rim15s (tpk rim15s) spores were viable. In a complementary experiment, a tpk rim15 $\Delta$ strain was transformed either with a plasmid that allows gal actoseinducible expression of RIM15 (Y C plF2-RIM15) or with the corresponding control plasmid (YCplF2). As expected, tpk rim15 $\Delta$ cells containing the control plasmid were able to grow on both glucose- and galactose-containing medium. In contrast, tpk rim15 $\Delta$ cells containing YCplF2-RIM 15 were able to grow on glucose-containing medium but failed to grow on galactose-containing medium (Fig. 2). Together, these results show that the loss of Rim15p suppresses the lethal effect of total IOSS of CAPK.

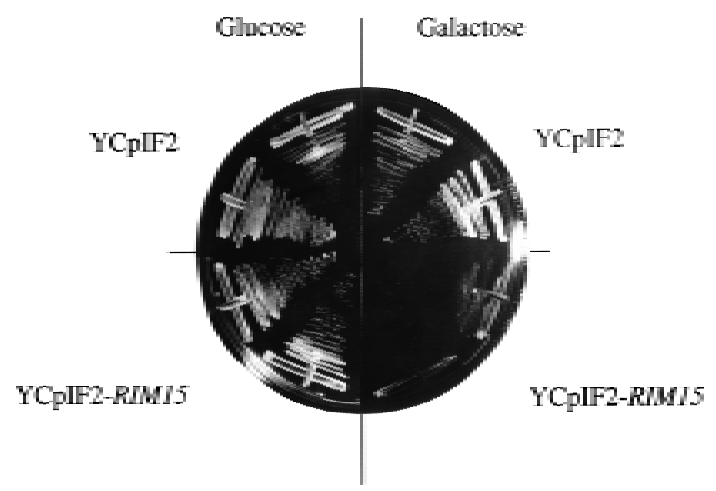

Figure2. Suppression of the tpk growth defect by rim15 15 . tpk1 tpk2 tpk3 rim15 $\Delta$ cells (N B13-14D) were transformed with plasmids Y CplF2 (control) and Y CplF2-RIM 15 (allowing gal actosedependent expression of RIM 15), streaked on SD media containing either glucose or gal actose as carbon source, and incubated for 4 days at $30^{\circ} \mathrm{C}$.

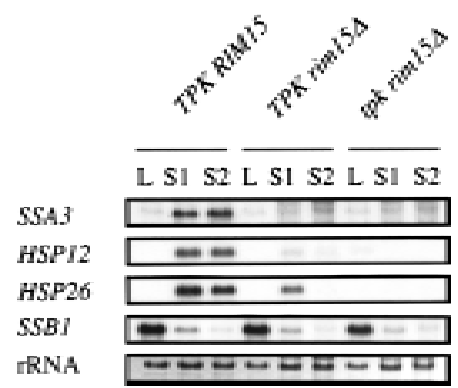

Figure 3. N orthern blot analysis of gene expression in exponentially growing and stationary phase TPK RIM 15 (SP1), TPK rim15s (N B13-1D), and tpk rim15 $($ N B13-14D) cells. Total RN A was extracted from log phase $(\mathrm{L})$ and stationary phase (S1, 2 days; S2, 4 days after glucose depletion) cells grown in YPD medium. For further details see Fig. 1, legend.

Because tpk rim $15 \Delta$ cells were viable, we were able to compare TPK rim15 $\Delta$ and tpk rim15 $\Delta$ cells and to examine whether, as expected for a downstream effector, rim15 $\Delta$ was epistatic over tpk mutations with respect to various stationary-phase-associated phenotypes. SSA3, HSP12, and HSP26 were repressed in logarithmically growing wild-type cells and induced in stationary phase cells (Fig. 3, lanes 1-3). In rim15 1 mutants, these genes were found to be repressed both in logarithmically growing and in stationary phase cells independent of the presence or absence of a functional TPK gene (Fig. 3, lanes 4-9). As a control for the physi ol ogi cal status of the cells, SSB1 was shown to be highly expressed in log phase cells and repressed in stationary phase cells of all three strains (Fig. 3, lanes 1-9). Like TPK rim15 $\Delta$ cells, tpk rim15 cells were also defective for the accumulation of trehalose $(0.027 \pm 0.005 \mathrm{gram} / \mathrm{gram}$ protein vs. $<0.01 \mathrm{gram} /$ gram protein for TPK rim15 $\Delta$ cells). Thus, rim15 $\Delta$ is largel y epistatic over tpk mutations with respect to these hallmarks of stationary phase (i.e. transcriptional activation/derepression of SSA3, HSP12, and HSP26 and trehalose accumulation). In contrast, tpk rim $15 \Delta$ cells had reduced growth rates at $30^{\circ} \mathrm{C}(0.16 \pm 0.01 / \mathrm{hr}$ versus $0.27 \pm 0.01 / \mathrm{hr}$ for TPK rim15 $\Delta$ cells), exhibited higher levels of thermotolerance $(6.3 \pm 1.6 \%$ vs. $0.07 \pm 0.01 \%$ survival after incubation for $20 \mathrm{~min}$ at $53^{\circ} \mathrm{C}$ for TPK rim15 $\Delta$ cells) and higher rates of survival in stationary phase $(50.7 \pm 9.8 \%$ vs. $4.6 \pm 0.8 \%$ after 10 days in stationary phase for TPK rim15 $\Delta$ cells), and hyperaccumulated glycogen (as measured by iodine staining) when compared with TPK rim15 cells. Thus, the TPK status still affected these phenotypes in rim15 $\Delta$ cells. The significance of these results is discussed below.

RIM 15 overexpression suppresses bcy1-1, exacerbates the growth defect of a strain partially compromised for CAPK activity, and partially mimics a nutrient limited state in wild-type cells

The data presented above suggest that Rim15p activity may be under direct or indi rect negative control by CAPK and that Rim15p may be responsible for the induction of 
Table 4. Suppression of bcy1-1 phenotypes by overexpression of RIM 15

\begin{tabular}{lllcrc}
\hline Strain & $\begin{array}{l}\text { Relevant } \\
\text { genotype }\end{array}$ & Plasmid & $\begin{array}{c}\text { Trehalose } \\
\text { (gram/gram protein) }\end{array}$ & $\begin{array}{c}\text { SSA3-lacZ induction } \\
\text { (Miller units) }\end{array}$ & $\begin{array}{c}\text { Thermotolerance } \\
\text { (\% survival) }\end{array}$ \\
\hline SP1 & BCY1 & YCPADH1 & $0.39 \pm 0.05$ & $137.8 \pm 37.5$ & $39.8 \pm 3.7$ \\
SP1 & BCY1 & YCPADH1-RIM15 & $0.56 \pm 0.11$ & $299.9 \pm 76.0$ & $73.0 \pm 2.4$ \\
T16-11A & bcy1-1 & YCPADH1 & $0.12 \pm 0.06$ & $41.4 \pm 11.1$ & $12.6 \pm 2.9$ \\
T16-11A & bcy1-1 & YCPADH1-RIM15 & $0.24 \pm 0.02$ & $123.9 \pm 25.7$ & $43.0 \pm 10.9$ \\
\hline
\end{tabular}

Cells were grown to stationary phase (5 days) on SD medium containing $1 \%$ glucose. Values represent means \pm S.D.S of three to six independent experiments. $\beta$-Galactosidase activities were measured to monitor the induction of an SSA3-IacZ fusion gene (from plasmid pWB204 $\Delta$-236). Thermotolerance was measured as the survival following a heat shock for $20 \mathrm{~min}$ at $50^{\circ} \mathrm{C}$.

a subset of the physiological changes triggered by nutrient limitation including the synthesis of trehal ose and the transcriptional derepression (or activation) of SSA3, HSP12, and HSP26. If this model were correct, one would expect that overexpression of RIM15 should, on the one hand, revert phenotypes associated with uncontrolled, constitutive activation of CAPK and, on the other hand, exacerbate phenotypes associated with attenuated CAPK activity. In accordance with these expectations, overexpression of RIM 15 under the control of the ADH 1 promoter (YCpADH1-RIM15) partially suppressed the defect in trehalose accumulation and completely suppressed the defects in SSA3-lacZ induction (from pWB204-236) and thermotolerance acquisition of bcy1-1 cells entering stationary phase (Table 4 ). In addition, overexpression of RIM15 caused a significant increase of stationary-phase-induced trehal ose accumulation, SSA3-lacZ induction, and thermotolerance acquisition in wild-type cells (Table 4; see also below). Furthermore, overexpression of RIM 15 was found to exacerbate the growth defect of a temperature-sensitive adenylate cyclase mutant (cdc35-10): Although this particular mutant grew well at $34^{\circ} \mathrm{C}$ and at $27^{\circ} \mathrm{C}$ when harboring the control plasmid, it was defective for growth at $34^{\circ} \mathrm{C}$, but not at $27^{\circ} \mathrm{C}$, when overexpressing RIM 15 (Fig. 4).

To study further the effects of RIM 15 overexpression in wild-type cells, strain YEF473 containing the reporter plasmid pWB204 4 -236 was transformed with either YCpIF2-RIM 15 (allowing galactose-inducible expression of RIM 15) or Y CpIF2 (control) and analyzed for trehal ose levels, SSA3-lacZ induction, and thermotolerance after growth for $16 \mathrm{hr}$ (log phase) or 4 days (stationary phase) on galactose-containing medium. As shown in Table 5, overexpression of RIM15 significantly enhanced the levels of trehal ose, SSA3-lacZ induction, and thermotolerance in log as well as in stationary-phase cells when compared with the corresponding control. Thus, physiol ogical adaptations associated with stationary phase are partially induced in log-phase cells and enhanced in stationary-phase cells by overexpression of RIM 15.

Rim15p protein kinase activity is negatively regulated by CAPK-dependent phosphorylation

The epistasis analyses presented above suggest that Rim15p serves to inhibit cell growth and to promote stationary phase entry and that its kinase activity may be attenuated by direct CAPK-dependent phosphorylation. This would mark Rim15p as the first protein kinase known to constitute a downstream effector of CAPK in S. cerevisiae. To test this model, we first analyzed whether Rim15p has protein kinase activity and whether it could phosphorylate itself in vitro. To this end, a functional GST-Rim15p fusion protein was expressed in wild-type $\mathrm{S}$. cerevisiae cells, purified by glutathione affinity chromatography, and incubated with $\left[\gamma^{-}{ }^{32} \mathrm{P}\right] \mathrm{ATP}$. This procedure resulted in phosphorylation of a 223-kD polypeptide (expected size for GST-Rim15p) and of a variety of smaller polypeptides (Fig. 5A). Immunoblot analysis with anti-GST antibodies al so revealed the presence of a 223-kD polypeptide as well as a similar array of smaller polypeptides that were not present in GST control extracts (data not shown). From these data, we infer that the 223-kD band corresponds to the GST-Rim15p and that the smal ler bands represent proteolytic fragments of it. To eliminate the possibility that in vitro Rim15p phosphorylation is catalyzed by a protein kinase coprecipitating with GST-Rim15p and to assess the extent of autophosphorylation, we examined the autophosphorylation activity of an ATP-binding-deficient GSTRim15p-K823Y fusion protein. This mutant fusion protein has lysine 823 , corresponding to the conserved lysine shown to be required for ATP binding and kinase activity of known protein kinases (Saraste et al. 1990),

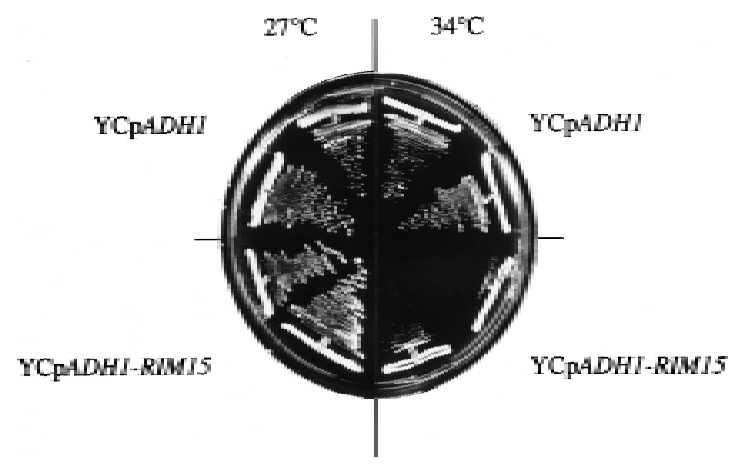

Figure 4. Overexpression of RIM 15 exacerbates the temperature-sensitive growth defect of a cdc35-10 mutant. Strain PD6517 (cdc35-10) was transformed with plasmids YCPADH 1 and YCPADH 1-RIM 15, streaked on SD medium, and incubated for 3 days at the temperatures indicated. 
Table 5. Effects of RIM 15 overexpression

\begin{tabular}{|c|c|c|c|c|c|c|c|}
\hline \multirow[b]{2}{*}{ Strain } & \multirow[b]{2}{*}{ Relevant genotype } & \multicolumn{2}{|c|}{$\begin{array}{c}\text { Trehalose } \\
\text { (gram/gram protein) }\end{array}$} & \multicolumn{2}{|c|}{$\begin{array}{l}\text { SSA3-lacZ induction } \\
\text { (Miller units) }\end{array}$} & \multicolumn{2}{|c|}{$\begin{array}{c}\text { Thermotolerance } \\
\text { (\% survival) }\end{array}$} \\
\hline & & $\log$ & stat & $\log$ & stat & $\log$ & stat \\
\hline YEF473 & wild-type (YCplF2) & $0.006 \pm 0.002$ & $0.238 \pm 0.030$ & $12.6 \pm 3.0$ & $429.0 \pm 61.9$ & $0.9 \pm 0.5$ & $77.1 \pm 8.5$ \\
\hline YEF473 & wild-type (Y CpIF2-RIM 15) & $0.063 \pm 0.008$ & $0.364 \pm 0.027$ & $37.0 \pm 3.7$ & $589.0 \pm 43.7$ & $4.9 \pm 1.6$ & $98.5 \pm 18.0$ \\
\hline
\end{tabular}

Cells were grown to log phase (log) or stationary phase (stat; 4 days) on SD medium containing $2 \%$ gal actose and $1 \%$ raffinose to induce GAL1-driven transcription of RIM 15 in YC pIF2-RIM 15. Values represent means \pm S.D.S of three experiments. $\beta$-Gal actosidase activites were measured to monitor the induction of an SSA 3-lacZ fusion gene (from plasmid pWB204 $\Delta-236$ ). Thermotolerance was measured as the survival following a heat shock for $4 \mathrm{~min}$ (log-phase cells) or $20 \mathrm{~min}$ (stationary-phase cells) at $50^{\circ} \mathrm{C}$.

replaced by a tyrosine. As shown in Figure 5A, autophosphorylation of GST-Rim15p-K823Y was reduced by about $90 \%$. Thus, the major part of the Rim15p in vitro phosphorylation results from an autocatal ytic reaction.

Then we examined the role of CAPK in Rim15p phosphorylation. Incubation of GST-Rim15p and GSTRim15p-K823Y with bovine CAPK and [ $\gamma$ - ${ }^{32}$ P]ATP I ed to extensive phosphorylation of both fusion proteins (Fig. $5 \mathrm{~A}$; similar results were obtained using bacterially expressed GST-Tpk1p instead of bovine cAPK. Since we found the activity of GST-Tpk $1 p$ to be highly unstable, we used bovine CAPK in our experiments). The lower phosphorylation level after cAPK-treatment of GSTRim15p-K823Y compared with GST-Rim15p may be explained by the absence of autophosphorylation in the former fusion protein. Because Rim15p can be phosphorylated by CAPK, we addressed the significance of this event for Rim15p activity. For this assay, $\alpha$-casein, which was found to be efficiently phosphorylated by Rim15p, was used as exogenous substrate. As shown in Figure 5B, the ability of Rim15p to phosphorylate $\alpha$-casein was significantly reduced $(>75 \%)$ by preincubation with bovine CAPK. This CAPK-mediated reduction could be completely prevented if CAPK inhibitor was present

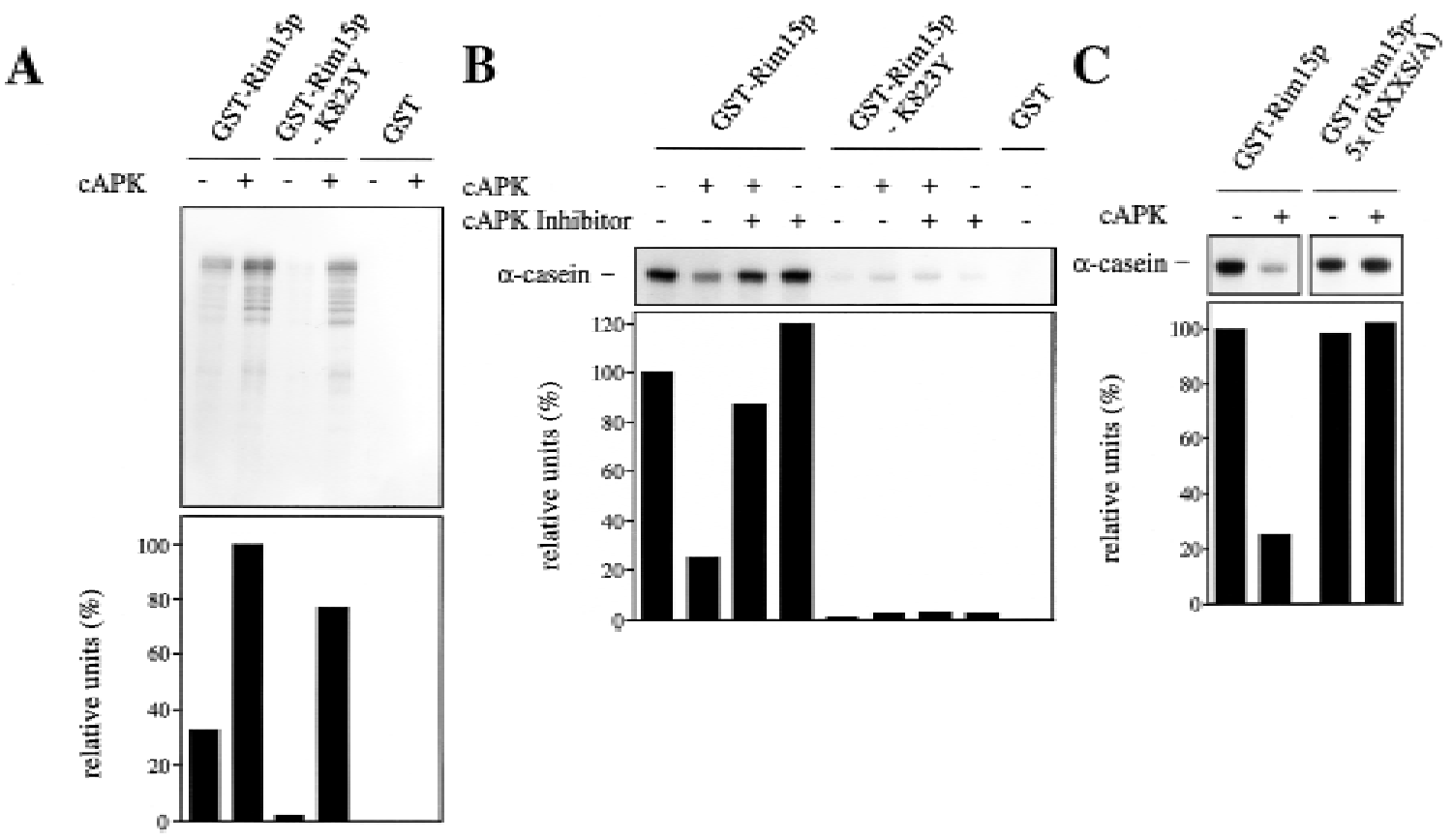

Figure 5. CAPK-dependent phosphorylation of Rim15p inhibits its kinase activity. (A) GST-Rim15p, GST-Rim15p-K823Y, and GST proteins were purified and analyzed for autophosphorylation activity and their potential to be phosphorylated by cAPK. Accordingly, equal amounts of the fusion proteins (verified by immunoblotting with anti-GST antibodies) were incubated with [ $\left.\gamma-{ }^{32} \mathrm{P}\right] \mathrm{ATP}$ either in the absence (-CAPK) or in the presence (+CAPK) of CAPK as described in Materials and Methods. Phosphorylation levels were quantitated by Phosphorlmager analysis and expressed as percent of the GST-Rim15p-phosphorylation level (+cAPK). (B) To analyze the effect of cAPK-dependent phosphorylation of Rim15p, equal amounts of GST-Rim15p, GST-Rim15p-K823Y, and GST (verified by immunoblotting as in A) were preincubated with unlabeled ATP and either no further additions, with cAPK, with CAPK and CAPK inhibitor, or with CAPK inhibitor al one, as indicated. The samples were washed extensi vely and assayed for $\alpha$-casein phosphorylation in the presence of CAPK inhibitor and $\left[\gamma^{-32}\right.$ P]ATP. The level $s$ of $\alpha$-casein phosphorylation were quantitated by Phosphorlmager analysis and expressed as percent of the control (level of $\alpha$-casein phosphorylation after preincubation of GST-Rim15p in the absence of both CAPK and CAPK inhibitor). (C) Equal amounts of GST-Rim15p and GST-Rim15p-S709A/S1094A/S1416A/ S1463A/S1661A [GSTRim15p-5x(RRXS/A)] were analyzed as in B. 
during the preincubation. In control experiments with GST or GST-Rim15p-K823Y we found no detectable or only residual $(<4 \%)$ phosphorylation of $\alpha$-casein, respectively. In accordance with these results, the corresponding GST and GST-rim15 ${ }^{\mathrm{K} 823 Y}$ genes, but not the GST-

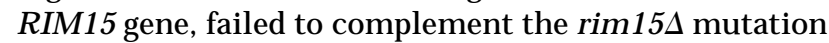
(data not shown).

As mentioned above, the predicted Rim15p amino acid sequence contains five A rg Arg X Ser consensus sites for CAPK phosphorylation (Edelman et al. 1987). If Rim15p kinase activity is down-regulated by CAPK-dependent phosphorylation, replacement of Ser with Ala at these five consensus sites should yield a cAPK-unresponsive Rim15p mutant protein. As expected, we found that a GST-Rim15p-S709A/S1094A/S1416A/S1463A/S1661A quintuple mutant protein [GST-Rim15p-5x(RRXS/A)] could not be inhibited in vitro by preincubation with CAPK (Fig. 5C). Taken together, these data show that CAPK-mediated phosphorylation of Rim15p inhibits its kinase activity.

\section{Discussion}

We identified the Rim15p protein kinase in a two-hybrid screen for potential interactors with Tpslp, the small subunit of the Tre6P synthase. Loss of Rim15p was found to cause a highly pleiotropic phenotype in cells entering stationary phase, including a defect in trehal ose synthesis, which suggests a role for Rim15p in nutrient signal transduction. Our results are most simply interpreted in a model in which Rim15p functions in the Ras/cAMP pathway downstream of CAPK to regulate a set of physiological adaptations necessary for proper entry into stationary phase. Several observations support such a model. First, deletion of RIM15 results in a defective response to nutrient limitation of mutant cells entering stationary phase that is reminiscent of the effects caused by mutations that constitutively activate CAPK (e.g., bcy1 and RAS2 ${ }^{\mathrm{Val}}{ }^{19}$ ). Accordingly, rim15 cells are seriously defective in trehalose accumulation, in transcriptional derepression of SSA3, HSP12, and HSP26, in induction of thermotolerance and starvation resistance, as well as in proper $\mathrm{G}_{1}$ arrest when entering stationary phase. Second, deletion of RIM 15 suppresses the growth defect at el evated temperatures of a temperature-sensitive adenylate cyclase mutant (cdc35-10) and all ows growth of cells that lack all three CAPK-encoding genes. Third, overexpression of RIM 15 suppresses the defects in trehalose accumulation, transcriptional derepression of SSA3, and thermotolerance acquisition in stationary cells of a bcyl-1 mutant, exacerbates the growth defect of a strain compromised for CAPK activity (cdc35-10), and partially induces a starvation response in logarithmically growing wild-type cells. Fourth, CAPKmediated phosphorylation of Rim15p, but not of a GST Rim15p-5x(RRXS/A) quintupl e mutant protein with Serto-Ala mutations at the consensus sites for CAPK phosphorylation, results in a strong reduction of the Rim15p protein kinase activity in vitro.

Despite the broad physiological overlap of the effects of cAPK hyperactivity and of loss of Rim15p, there are some notable differences. In contrast to rim15s, mutations that cause constitutive activation of CAPK such as bcy1 or RAS2 ${ }^{\text {Val } 19}$ are generally associated with constitutive activation of neutral trehalase, complete inability to accumulate glycogen, and gluconeogenic growth defects (Kataoka et al. 1984; Toda et al. 1987; Cameron et al. 1988). A model that may account for these differences is that CAPK constitutes a point of divergence in the Ras/CAMP pathway and that Rim15p acts beyond this specific point (Fig. 6). Accordingly, CA PK may on the one hand transmit the signal of the Ras/CAMP pathway to $\operatorname{Rim} 15 p$ and on the other hand directly control several other cellular mechanisms such as the activation of neutral trehal ase (for review, see Thevelein 1996), the inhibition of glycogen synthesis (Hardy et al. 1994 and references therein), and the inhibition of gluconeogenic growth (Müller and Holzer 1981; Mazón et al. 1982; François et al. 1984; Cherry et al. 1989). If this model were correct, rim $15 \Delta$ should be epistatic to tpk mutations with respect to some but not all phenotypes. Our results support such a conclusion. Accordingly, we found that a tpk rim15 $\Delta$ strain, like aTPK rim15 $\Delta$ strain, was defective for derepression of SSA 3, HSP12, and HSP26 as well as for trehalose accumulation upon entry into stationary phase, suggesting that these processes are downstream of and controlled by Rim $15 \mathrm{p}$. In contrast, the tpk rim15 $\Delta$ strain was still found to exhibit a reduced

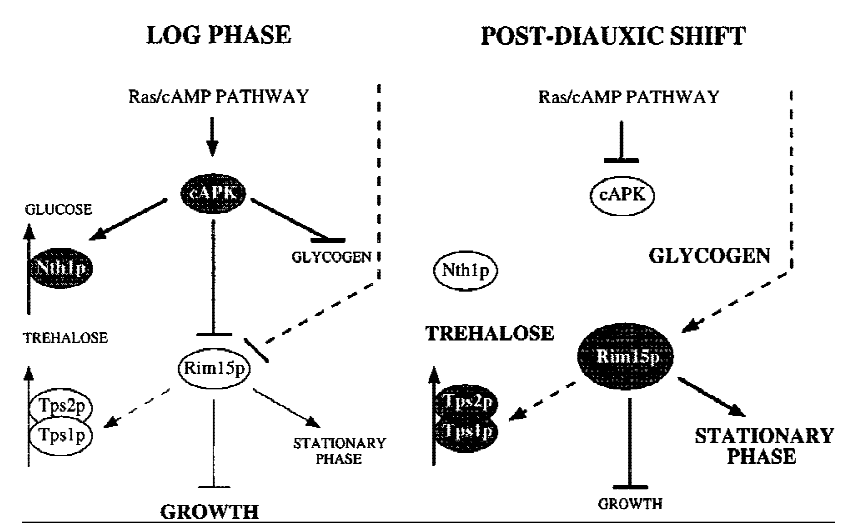

Figure 6. Model for the CAMP-dependent protein kinase (CAPK)-Rim15p pathway. Glucose-repression as well as posttranslational inhibition via cAPK-dependent phosphorylation, and potentially an additional yet-to-be-identified mechanism, result in low Rim15p kinase activity in log phase. During the postdiauxic shift, glucose derepression of RIM 15 (illustrated by the increase in size of the Rim15p protein), down-regulation of CAPK-dependent inhibition, and potential activation by yet-tobe-identified mechanisms result in high Rim15p kinase activity. Rim15p acts as a positive regulator of stationary phase entry and, consequently, as a negative regulator of growth. (Arrow) Positive interaction; (bar) negative interaction. Bold arrows and bars denote high activity. Dashed arrows and bars refer to potential interactions. Accumulation of trehal ose and glycogen is indicated with bold letters. Inactive proteins are on white and active proteins are on shaded backgrounds. N thlp, Tpslp, and Tps2p denote neutral trehalase, Tre6P synthase, and Tre6P phosphatase, respectively. For further details, see text. 
growth rate, to acquire higher levels of thermotolerance, to hyperaccumulate glycogen, and-possibly as a result of the higher gl ycogen content-to have significantly enhanced levels of stationary phase survival when compared to the TPK rim15 $\Delta$ strain. Thus, control over these processes may be exerted to some extent at the level of CAPK and therefore be at least partially independent of Rim15p. In this context, the seemingly contradictory finding that stationary TPK rim $15 \Delta$ mutants had reduced levels of glycogen may be reconciled with our model if Rim15p would be involved in mechanisms of cAPK feedback inhibition. We are currently exploring this possi bility in further detail.

Several protein kinases whose functions may partially overlap with the ones of the Ras/CAMP pathway have been described previously. One of these protein kinases is Snf1p, which functions primarily in glucose repression by its negative control of transcriptional factors such as Miglp (for review, see Ronne 1995). Genetic studies indicated that not all Snf1p functions are mediated by Miglp, though, and that Snflp controls glycogen accumulation, acquisition of thermotolerance, and proper $G_{1}$ arrest upon depletion of external glucose in parallel and antagonistically to CAPK (Thompson-Jaeger et al. 1991; Woods et al. 1994; Huang et al. 1996). In this context, two other genes encoding protein kinases, namely $\mathrm{SCH} 9$ and $Y A K 1$, have been isolated by genetic screens for growth-rel ated effectors of CAPK (T oda et al. 1988; Garrett and Broach 1989). However, their corresponding gene products may both define separate nutrient signaling pathways that also act parallel to the Ras/CAMP pathway (Toda et al. 1988; Denis and Audino 1991; Garrett et al. 1991; Thompson-Jaeger et al. 1991; Hartley et al. 1994). Thus, even though the roles of Snf1, Sch9, and Yak1 in the Ras/cAM P pathway are not understood, the available evidence suggests that all three protein kinases may functionally overlap with and act in parallel to the Ras/cAMP pathway. Therefore, Rim15p appears to be the first protein kinase identified as constituting a downstream effector of CAPK in S. cerevisiae.

Consistent with both the proposed role of Rim15p as an activator of stationary phase entry and the observation that rim $15 \Delta$ caused no obvious defect in exponentially, glucose-grown cells, the level of RIM 15 mRNA and Rim15p protein were found to be very low during growth on glucose and to increase si gnificantly upon gl ucose exhaustion (Vidan and Mitchell 1997; this study). Because RIM 15 is transcriptional ly repressed in the presence of glucose, it is not surprising that replacement of RIM15 with the rim15 15 (RRXS/A) mutant gene did not cause any significant effects in exponentially growing cells (data not shown). However, we also found that the effects of rim15 $15^{5 \times(R \times S / A)}$ overexpression did not significantly differ from the ones observed following RIM 15 overexpression (i.e., both genes caused a similar, partial induction of stationary phase characteristics in exponentially growing cells; Table 5 and data not shown). This observation may be explained if overexpression of RIM15 results in Rim15p protein levels that exceed a certain threshold level beyond which Rim15p may es- cape CAPK-dependent down-regulation. Accordingly, maximal induction of stationary phase characteristics in log phase cells would al ready be achieved by overexpression of the RIM 15 wild-type gene. The rather moderate level of induction of these stationary phase characteristics in log phase cells may be attributable to the presence of activated CAPK, which indirectly counteracts the effects of Rim15p (e.g., by activation of neutral trehalase), and/or to potential CAPK-independent mechanisms involved in the control of Rim15p kinase activity. The latter would raise the intriguing possibility that Rim15p-besides the observed regulation by glucose repression and CAPK-dependent inhibition-is subjected to down-regulation and/or activation by at least one other, yet unidentified CAMP-independent nutrient signaling pathway. In this context, it is worth noting that a previous report suggested the existence of CAMP-independent mechanisms for regulation of proper stationary phase entry including trehal ose accumulation, glycogen synthesis, and the development of thermotolerance (Cameron et al. 1988). Therefore, future studies should address the question of whether any of the potentially separate nutrient signaling pathways may converge at and be integrated by Rim15p.

A further interesting aspect of our study is the possibility that the TPS1-encoded Tre6P synthase may be a direct target of Rim15p. This suggestion is supported by several observations. First, Rim15p shows specific twohybrid interaction with Tps1p. Second, Ioss of Rim15p causes a defect in stationary phase-induced trehal ose accumulation. Third, overexpression of RIM 15 not only significantly induces trehalose synthesis in log-phase cells but also enhances trehalose accumulation in stationary phase cells. Even though these data do not exclude the possibility that Rim15p activates Tre6P synthase rather indirectly, they would be consistent with a model in which Tpslp is positively regulated by Rim15p-dependent phosphorylation. As intriguing as this model may be, it is not easily reconciled with the observation that the in vitro-measured T re6P synthase of stationary phase rim $15 \Delta / \operatorname{rim} 15 \Delta$ cells was found to be fully active, even though no trehalose was formed in vivo. This inconsistency may be explained, however, if Tre6P synthase were artificially activated by limited proteolysis during the sampling procedure as has been suggested earlier (Londesborough and Vuorio 1991; VicenteSoler et al. 1991). Taken together, it is clear that further detailed biochemical characterization of Tpslp is necessary to elucidate whether its activity may be regulated via phosphorylation/dephosphorylation and whether Rim15p is directly or rather indirectly involved in such a process. Because recent evidence suggested that T pslp is also involved in the control of glucose flux into glycolysis, possibly through a specific mechanism independent of trehalose synthesis (for review, see Thevelein and Hohmann 1995), such anal yses may not only contribute to our understanding of the regulation of trehalose synthesis but may al so help defining the potential trehalose synthesis-independent function of the yeast Tps1p protein. 
Recently, Rim15p was identified independently through a mutation that caused reduced expression of IME2 (Vidan and Mitchell 1997). Current knowledge suggests that Rim15p may act to stimulate formation of the Ime1-U me6 complex, which in turn acts as a transcriptional activator of early meiotic gene expression (Bowdish et al. 1995; Rubin-Bejerano et al. 1996; Vidan and Mitchell 1997). In view of both these recent findings on Rim15p and the long standing suggestion that entry into meiosis is at least partially regulated by starvation through the Ras/cAM P pathway (M atsumoto et al. 1983; Smith and M itchell 1989; Matsuura et al. 1990), our present study, placing Rim15p immediately downstream of CAPK, may finally link the Ras/CAMP pathway to early meiotic gene expression.

\section{Materials and methods}

Strains, media, and microbiological and recombinant DNA methods

The S. cerevisiae strains used in this study are listed in Table 1. Escherichia coli strain JMB9 ( $\left[\mathrm{r}^{-} \mathrm{m}^{+}\right] \mathrm{trpF}$ ) was used to rescue pJG4-5-based plasmids from strain EGY 48 as described earlier (De Virgilio et al. 1996). Other plasmid manipulations were performed in E. coli strain DH5 $\alpha$ (GIBCO BRL) with standard procedures (Sambrook et al. 1989). Y east and E. coli media, including the rich, glucose-containing medium (YPD), the defined media (SD with appropriate supplements), and sporulation medium were prepared by standard recipes (Sambrook et al. 1989; Rose et al. 1990). Standard procedures of yeast genetics and molecular biology were used (Guthrie and Fink 1991; Sambrook et al. 1989). Y east transformations were performed with a modification of the $\mathrm{Li}^{+}$-ion method (Gietz et al. 1992). Sporulation experiments were performed essentially as described by $D e$ Virgilio et al. (1996).

\section{DNA sequencing and sequence analyses}

Sequences were obtained from double-stranded plasmid DNA, by use of the dideoxy chain termination method (Sanger et al. 1977) with $\Delta$ Tth DNA polymerase (Toyobo, Japan) and [ $\alpha-$ ${ }^{33}$ P JdATP (Hartmann Analytic, Braunschweig, Germany). The University of Wisconsin Genetics Computer Group (GCG) programs were used to compile and analyze sequence data. Alignments were performed with the GAP, PILEUP, and PRETTY comparison programs.

\section{Two-hybrid analysis}

The interactions of Rim15p with the subunits of the Tre6P synthase complex were tested by two-hybrid analysis (Fields and Sternglanz 1994) with the LexA system described in detail elsewhere (Gyuris et al. 1993). The various full-length Tre6P synthase complex subunits were fused to the LexA DBD coding sequences in plasmid pEG202 (Zervos et al. 1993) as described by Reinders et al. (1997). Plasmid pJ G4-5-RIM 15-P, which contains a fragment of RIM 15 fused to the AD moiety of pJG4-5, was isolated in a two-hybrid screen for proteins that interact with Tpslp. Strain EGY48 (Table 1) containing the LexAoplacZ reporter plasmid pSH18-34 (Gyuris et al. 1993) was cotransformed with a pEG202-derived plasmid expressing a LexA DBD fusion protein and with pJG4-5 or pJG4-5-RIM15-P. $\beta$ Galactosidase activities (in Miller units) were then assessed in three independent clones of each strain grown for $16 \mathrm{hr}$ at $27^{\circ} \mathrm{C}$ in minimal medium (containing $2 \% \mathrm{wt} / \mathrm{vol}$ galactose, $1 \% \mathrm{wt} /$ vol raffinose, and $20 \mu \mathrm{g} / \mathrm{ml}$ leucine).

\section{Cloning and deletion of RIM 15}

The 0.9-kb EcoRI fragment of one RIM 15 two-hybrid library plasmid was labeled with $\left[\alpha{ }^{32} \mathrm{P}\right] \mathrm{dATP}$ (Hartmann Analytic) by use of the Prime-It II Random Primer Labeling Kit (Stratagene) and subsequently used to screen a genomic DN A library (in pSey8; kindly provided by M. Hall, Biocenter, Basel, Switzerland) as described by Sambrook et al. (1989). Three positive clones were found to contain overlapping fragments that together covered the entire RIM15 gene. A segment of $6313 \mathrm{bp}$ containing the entire RIM 15 gene including flanking sequences was sequenced on both strands (submitted as TAK1, EMBL database accession no. AJ001030).

The complete RIM 15 coding region was deleted by the PCR method (Wach et al. 1994) with plasmid pFA6a (kanMX2) as template and Taq DNA polymerase (Boehringer Mannheim). Oligonucleotides that contained 43 and 40 nucleotides immediately upstream and downstream, respectively, of the RIM 15 coding region, and 19 and 22 nucleotides upstream and downstream, respectively, of the kanMX 2 module were used to create a PCR product that contained flanking sequences of RIM 15 separated by the kanMX2 module. This DN A was used to transform strains YEF473, PD6517, and S7-7A $\times$ S7-5A to construct AR1, NB11, and NB13, respectively (Table 1). Transformants that had RIM 15 replaced with the kanMX2 module were identified by their geneticin-resistant growth and confirmed by PCR and/or Southern blot analysis (data not shown).

\section{Enzyme assays and determination of metabolite levels}

The activities of Tre6P synthase and neutral trehalase were measured in permeabilized cells essentially as described by De Virgilio et al. (1993, 1994). Invertase activity was determined in crude extracts according to an established protocol (Goldstein and Lampen 1975). $\beta$-Galactosi dase activity was assayed using o-nitrophenyl- $\beta$-D-gal actosi de as substrate (M iller 1972). Trehalose and glycogen were measured by the procedures of De Virgilio et al. (1993) and Lillie and Pringle (1980), respectively. Protein concentrations were either measured by the Bio-Rad protein assay according to the manufacturer's instructions or by a modified Lowry assay (Peterson 1977) with BSA as standard.

Preparation and Northern analysis of RNA

Extraction of total cellular RNA was performed as described previously (Piper 1994). For Northern analysis, $10 \mu \mathrm{g}$ of total RNA was separated on $1.1 \%$ agarose gels containing $0.65 \mathrm{M}$ formal dehyde, transferred to nitrocellul ose membranes (BA 83; Schleicher and Schuell, Germany) in 20× SSC, and hybridized with [ $\left.{ }^{32} \mathrm{P}\right] \mathrm{dAT} P$-labeled DN A fragments that were amplified by PCR from genomic DNA. The primers used for PCR were as follows, with the forward primers listed first and the fragment sizes generated given in parentheses: RIM 15, 5'-CTGATTCGCCGTCACAAGTTTGTCCCACATAAGTCG-3' and 5'-CGTATTGGTAGCTGCGATAACGTCTGAAGATAATAG-3' kb); SSA 3, 5'-ATGTCTAGAGCAGTTGGT-3' and 5'-ATCAACCTCTTCCACTGT-3' (1.95 kb); HSP12, 5'-ATGTCTGACGCAGGTAGAAAAGGATTC-3' and 5'-TTACTTCTTGGTTGGGTCTTCTTCACC-3' (0.33 kb); HSP26, 5'-ATGTCATTTAACAGTCCATTTTTTGATTTC-3' and 5'-TTAGTTACCCCACGATTCTTGAGAACAAAC-3' (0.64 kb); UBI4, 5'-ATGCAGATTTTCGTCAAG-3' and 5'-GTTACCA CCCCTCAACCT-3' 
(1.14 kb); ADH2, 5'-ATGTCTATTCCAGAAACTCAAAAAGCC-3' and 5'-TTATTTAGAAGTGTCAACAACGTATC-3' (1.05 kb); and SSB1, 5'-ATGGCTGAAGGTGTTTTCCAAGGTGC-3' and 5'-TTAACGAGAAGACAGGCCTTGGTGAC-3' (1.84 kb).

\section{Plasmid constructions}

For construction of the gal actose-inducible GAL1-RIM 15 al lele, the full-length RIM 15 coding sequence was amplified by use of the Expand Long Template PCR System (Boehringer Mannheim) and genomic DN A as template. Sall and Notl restriction sites were introduced immediately upstream of the ATG start codon and 86 bp downstream of the stop codon, respectively. This PCR product was cloned at the Sall-Notl site of YCplF2 (Foreman and Davis 1994) to yield YCplF2-RIM15. Plasmids YCplF2-GST and YCplF2-GST-RIM15 were constructed by cloning of a PCR-generated Sall-Sall fragment, containing the 672 nucleotides downstream of and including the GST start codon, at the Sall site of YCplF2 and YCplF2-RIM15, respectively. Plasmids YCPADH 1 and YCpADH1-RIM 15 were constructed by replacement of the GAL1 promoter-containing Apal-Sall fragments of YCpIF2 and YCpIF2-RIM15, respectively, with a PCR-generated A pal-Sall fragment containing the 854 nucleotides upstream of and including the ADH1 start codon. Plasmids YCpIF2-GST-RIM15 ${ }^{\mathrm{K} 823 \mathrm{Y}}$ and YCpIF2-GSTRIM 15 $5709 \mathrm{~A} / \mathrm{S1094A} / \mathrm{S1416 \textrm {A } / \mathrm { S } 1 4 6 3 \mathrm { A } / \mathrm { S } 1 6 6 1 \mathrm { A }}$ were constructed with the QuickChange Site-Directed Mutagenesis Kit (Stratagene) with the appropriate primers that introduced the corresponding mutations and Y C PIF2-GST-RIM 15 as template. All mutations introduced were confirmed by subsequent sequencing.

\section{Protein kinase assays}

GST, GST-Rim15p, GST-Rim15p-K823Y, and GST-Rim15pS709A/S1094A/S1416A/S1463A/S1661A were expressed in wild-type S. cerevisiae cells from the GAL1 promoter. Cells were harvested in stationary phase after growth on YP medium containing $2 \%$ gal actose and $1 \%$ raffinose and disrupted by vortexing in lysis buffer [50 mM Tris- $\mathrm{HCl}$ at $\mathrm{pH} 7.5,0.1 \mathrm{M} \mathrm{N} \mathrm{aCl}, 1$ mM EDTA, 1\% NP-40, and one tablet of Complete Protease Inhibitor Cocktail (Boehringer Mannheim) per $50 \mathrm{ml}$ ] in the presence of acid-washed glass beads (0.4-mm diameter; $M$ erck). The extracts were clarified three times by centrifugation at $4^{\circ} \mathrm{C}$ in a microfuge at $17,000 \mathrm{rpm}, 10 \mathrm{~min}$ each time. The various GST fusions were purified from clarified cell extracts (containing $\sim 30 \mathrm{mg}$ protein per $\mathrm{ml}$ ) after a $4-\mathrm{hr}$ incubation at $4^{\circ} \mathrm{C}$ with glutathione-Sepharose beads (50 $\mathrm{\mu l} / \mathrm{ml}$; Pharmacia). Proteinbound beads were pelleted, washed four times with lysis buffer and three times with kinase buffer $(50 \mathrm{~mm}$ Tris- $\mathrm{HCl}$ at $\mathrm{pH} 7.5$, $20 \mathrm{~mm} \mathrm{M} \mathrm{gCl}, 1 \mathrm{~mm}$ DTT, $1 \mathrm{~mm}$ ATP, and one tablet of Complete Protease Inhibitor Cocktail per $50 \mathrm{ml}$ ). Kinase assays were performed at $30^{\circ} \mathrm{C}$ for $30 \mathrm{~min}$ in reaction buffer (kinase buffer containing $50 \mathrm{~mm} \mathrm{NaF}, 10 \mathrm{~mm} \mathrm{~N}$ a-orthovanadate, $15 \mathrm{~mm}$ p$\mathrm{NO}_{2}$-phenylphosphate, $50 \mathrm{~mm} \beta$-glycerophosphate, $5 \mathrm{~mm} \mathrm{Na}$ pyrophosphate, $10 \mu \mathrm{Ci}\left[\gamma^{-32} \mathrm{P}\right] \mathrm{ATP}$, and, where indicated, 250 $\mu \mathrm{g} / \mathrm{ml} \alpha$-casein). Reactions were stopped by adding SDS-gel loading buffer and boiling for $5 \mathrm{~min}$ and were then subjected to SDS-PAGE. Gels were dried and exposed to X-ray film or to a Phosphorlmager. Quantitation of ${ }^{32} \mathrm{P}$ was performed with the Phosphor Analyst software (Bio-Rad).

To assay in vitro autophosphorylation and phosphorylation of Rim15p by bovine CAPK, wild-type or mutant GST-Rim15p fusion protein was purified as described above. Equal amounts of protein-bound beads $(10 \mu \mathrm{l})$ were resuspended in reaction buffer and incubated for $30 \mathrm{~min}$ at $30^{\circ} \mathrm{C}$ in the presence or absence of 1 unit of A kinase catalytic subunit (Sigma) and/or A kinase Inhibitor (Sigma). Reactions were stopped and analyzed as described above. When the effects of CAPK-dependent phosphorylation on Rim15p activity were monitored, reactions were incubated in $\left[\gamma^{32} \mathrm{P}\right] \mathrm{ATP}$-free reaction buffer in the presence or absence of 1 unit A kinase catalytic subunit, subsequently terminated by three washes with the same buffer (without A kinase catalytic subunit), and then the mixtures were incubated with $\alpha$-casein and $\left[\gamma^{32}\right.$ P]ATP as described above.

\section{Acknowledgments}

We thank J.M. Thevelein and E.A. Craig for strains and plasmids, respectively, and C. Funk and G. Vogel for assistance. This work was supported by the Swiss N ational Science Foundation, grants 42535.94 to A.W. and T.B. and 3100-052245.97/ 1 to C.D.V.

The publication costs of this article were defrayed in part by payment of page charges. This article must therefore be hereby marked 'advertisement' in accordance with 18 USC section 1734 solely to indicate this fact.

\section{References}

Becher dos Passos, J., M. Vanhal ewyn, R.L. Brandão, I.M . Castro, J.R. Nicoli, and J.M. Thevelein. 1992. Glucose-induced activation of plasma membrane $\mathrm{H}^{+}$-ATPase in mutants of the yeast Saccharomyces cerevisiae affected in CAMP metabolism, CAM P-dependent protein phosphorylation and the initiation of glycolysis. Biochim. Biophys. Acta 1136: 57-67.

Bell, W., P. Klaassen, M. Ohnacker, T. Boller, M. Herweijer, P. Schoppink, P. van der Zee, and A. Wiemken. 1992. Characterization of the 56-kDa subunit of yeast trehal ose-6-phosphate synthase and cloning of its gene reveal its identity with the product of CIF1, a regulator of carbon catabolite inactivation. Eur. J. Biochem. 209: 951-959.

Bi, E. and J.R. Pringle. 1996. ZDS1 and ZDS2, genes whose products may regulate $\mathrm{Cdc} 42 \mathrm{p}$ in Saccharomyces cerevisiae. Mol. Cell. Biol. 16: 5264-5275.

Boorstein, W.R. and E.A. Craig. 1990. Regulation of a yeast HSP70 gene by a CAMP responsive transcriptional control element. EMBO J. 9: 2543-2553.

Bowdish, K.S., H.E. Yuan, and A.P. Mitchell. 1995. Positive control of yeast meiotic genes by the negative regulator U M E6. Mol. Cell. Biol. 15: 2955-2961.

Broach, J.R. and R.J. Deschenes. 1990. The function of RAS genes in Saccharomyces cerevisiae. Adv. Cancer Res. 54: 79-139.

Cameron, S., L. Levin, M. Zoller, and M. Wigler. 1988. CAM Pindependent control of sporulation, glycogen metabolism, and heat shock resistance in S. cerevisiae. Cell 53: 555-566.

Cannon, J.F. and K. Tatchell. 1987. Characterization of Saccharomyces cerevisiae genes encoding subunits of cyclic AM Pdependent protein kinase. Mol. Cell. Biol. 7: 2653-2663.

Cherry, J.R., T.R. Johnson, C. Dollard, J.R. Shuster, and C.L. Denis. 1989. Cyclic AMP-dependent protein kinase phosphorylates and inactivates the yeast transcriptional activator ADR1. Cell 56: 409-419.

De Virgilio, C., N. Bürckert, W. Bell, P. Jenö, T. Boller, and A. Wiemken. 1993. Disruption of TPS2, the gene encoding the 100-kDa subunit of the trehalose-6-phosphate synthase/ phosphatase complex in Saccharomyces cerevisiae, causes accumulation of trehal ose-6-phosphate and loss of trehal ose6-phosphate phosphatase activity. Eur. J. Biochem. 212: 315323.

De Virgilio, C., T. Hottiger, J. Dominguez, T. Boller, and A. 
Wiemken. 1994. The role of trehal ose synthesis for the acquisition of thermotolerance in yeast. I. Genetic evidence that trehalose is a thermoprotectant. Eur. J. Biochem. 219: 179-186.

De Virgilio, C., D.J. DeM arini, and J.R. Pringle. 1996. SPR28, a sixth member of the septin gene family in Saccharomyces cerevisiae that is expressed specifically in sporulating cells. Microbiology 142: 2897-2905.

Denis, C.L. and D.C. Audino. 1991. The CCR1 (SNF1) and $\mathrm{SCH} 9$ protein kinases act independently of CAM P-dependent protein kinase and the transcriptional activator ADR1 in controlling yeast ADH2 expression. Mol. \& Gen. Genet. 229: 395-399.

Edel man, A.M., D.K. Blumenthal, and E.G. Krebs. 1987. Protein serine/threoninekinases. Annu. Rev. Biochem. 56: 567-613.

Fields, S. and R. Sternglanz. 1994. The two-hybrid system: an assay for protein-protein interactions. Trends Genet. 10: 286-292.

Foreman, P.K. and R.W. Davis. 1994. Cloning vectors for the synthesis of epitope-tagged, truncated and chimeric proteins in Saccharomyces cerevisiae. Gene 144: 63-68.

François, J., E. Van Schaftingen, and H.-G. Hers. 1984. The mechanism by which glucose increases fructose 2,6-bisphosphate concentration in Saccharomyces cerevisiae. A cyclicAM P-dependent activation of phosphofructokinase 2. Eur. J. Biochem. 145: 187-193.

Garrett, S. and J. Broach. 1989. Loss of Ras activity in Saccharomyces cerevisiae is suppressed by disruptions of a new kinase gene, YAK1, whose product may act downstream of the CAM P-dependent protein kinase. Genes \& Dev. 3: 13361348.

Garrett, S., M.M. Menold, and J.R. Broach. 1991. The Saccharomyces cerevisiae YAK1 gene encodes a protein kinase that is induced by arrest early in the cell cycle. Mol. Cell. Biol. 11: 4045-4052.

Gibbs, J.B. and M.S. M arshall. 1989. The ras oncogene-an important regulatory element in lower eucaryotic organisms. Microbiol. Rev. 53: 171-185.

Gietz, D., A. St. Jean, R.A. Woods, and R.H. Schiestl. 1992. Improved method for high efficiency transformation of intact yeast cells. Nucleic Acids Res. 20: 1425.

Goldstein, A. and J.O. Lampen. 1975. $\beta$-D-fructofuranosi de fructohydrolase from yeast. Methods Enzymol. 42: 504-511.

Guthrie, C. and G.R. Fink. 1991. Guide to yeast genetics and molecular biology. Methods Enzymol. 194.

Gyuris, J., E. Golemis, H. Chertkov, and R. Brent. 1993. Cdi1, a human $\mathrm{G}_{1}$ and $\mathrm{S}$ phase protein phosphatase that associates with Cdk2. Cell 75: 791-803.

Hardy, T.A., D. Huang, and P.J. Roach. 1994. Interactions between CAMP-dependent and SNF1 protein kinases in the control of glycogen accumulation in Saccharomyces cerevisiae. J. Biol. Chem. 269: 27907-27913.

Hartley, A.D., M.P. Ward, and S. Garrett. 1994. The Yak1 protein kinase of Saccharomyces cerevisiae moderates thermotolerance and inhibits growth by an Sch9 protein kinaseindependent mechanism. Genetics 136: 465-474.

Huang, D., I. Farkas, and P.J. Roach. 1996. Pho85p, a cyclindependent protein kinase, and the Snflp protein kinase act antagonistically to control glycogen accumulation in Saccharomyces cerevisiae. Mol. Cell. Biol. 16: 4357-4365.

Hunter, T. and G.D. Plowman. 1997. The protein kinases of budding yeast: Six score and more. Trends Biochem. Sci. 22: 18-22.

Kataoka, T., S. Powers, C. McGill, O. Fasano, J. Strathern, J. Broach, and M. Wigler. 1984. Genetic analysis of yeast RAS1 and RAS2 genes. Cell 37: 437-445.
Lillie, S.H. and J.R. Pringle. 1980. Reserve carbohydrate metabolism in Saccharomyces cerevisiae: Responses to nutrient limitation. J. Bacteriol. 143: 1384-1394.

Londesborough, J. and O. Vuorio. 1991. Trehal ose-6-phosphate synthase/ phosphatase complex from baker's yeast: Purification of a proteolytically activated form. J. Gen. Microbiol. 137: 323-330.

Matsumoto, K., I. Uno, and T. Ishikawa. 1983. Initiation of meiosis in yeast mutants defective in adenylate cyclase and cyclic AM P-dependent protein kinase. Cell 32: 417-423.

Matsuura, A., M. Treinin, H. Mitsuzawa, Y. Kassir, I. Uno, and G. Simchen. 1990. The adenylate cyclase/ protein kinase cascade regulates entry into meiosis in Saccharomyces cerevisiase through the gene IME1. EMBO J. 9: 3225-3232.

M azón, M.J., J.M. Gancedo, and C. Gancedo. 1982. Inactivation of yeast fructose-1,6-bisphosphatase. In vivo phosphorylation of the enzyme. J. Biol. Chem. 257: 1128-1130.

Miller, J.H. 1972. Experiments in molecular genetics. Cold Spring Harbor Laboratory, Cold Spring Harbor, NY.

Müller, D. and H. Holzer. 1981. Regulation of fructose-1,6-bisphosphatase in yeast by phosphorylation/dephosphorylation. Biochem. Biophys. Res. Comm. 103: 926-933.

Murakami, Y., M. N aitou, H. Hagiwara, T. Shibata, M. Ozawa, S. Sasanuma, M. Sasanuma, Y. Tsuchiya, E. Soeda, K. Yokoyama, M. Yamazaki, H. Tashiro, and T. Eki. 1995. Analysis of the nucleotide sequence of chromosome VI from Saccharomyces cerevisiae. Nat. Genet. 10: 261-268.

Panek, A.C., P.S. de Araujo, V.M. N eto, and A.D. Panek. 1987. Regulation of the trehalose-6-phosphate synthase complex in Saccharomyces. Curr. Genet. 11: 459-465.

Peterson, G.L. 1977. A simplification of the protein assay method of Lowry et al. which is more generally applicable. Anal. Biochem. 83: 346-356.

Piper, P.W. 1994. Measurement of transcription. In Molecular genetics of yeast. A practical approach. (ed. J.R. Johnston), pp. 135-146. IRL Press, Oxford, UK.

Reinders, A., N. Bürckert, S. Hohmann, J.M. Thevelein, T. Boller, A. Wiemken, and C. De Virgilio. 1997. Structural analysis of the subunits of the trehalose-6-phosphate synthase/phosphatase complex in Saccharomyces cerevisiae and their function during heat shock. Mol. Microbiol. 24: 687-695.

Ronne, H. 1995. Glucose repression in fungi. Trends Genet. 11: 12-17.

Rose, M.D., F. Winston, and P. Hieter. 1990. Methods in yeast genetics. Cold Spring Harbor Laboratory Press, Cold Spring Harbor, NY.

Rubin-Bejerano, I., S. M andel, K. Robzyk, and Y. Kassir. 1996. Induction of meiosis in Saccharomyces cerevisiae depends on conversion of the transcriptional repressor Ume6 to a positive regulator by its regulated association with the transcriptional activator Imel. Mol. Cell. Biol. 16: 2518-2526.

Sambrook, J., E.F. Fritsch, and T. Maniatis. 1989. Molecular cloning: A laboratory manual, 2nd ed. Cold Spring Harbor Laboratory Press, Cold Spring Harbor, NY.

Sanger, F., S. Nicklen, and A.R. Coulson. 1977. DN A sequencing with chain-terminating inhibitors. Proc. Natl. Acad. Sci. 74: 5463-5467.

Saraste, M., P.R. Sibbald, and A. Wittinghofer. 1990. The Ploop-a common motif in ATP- and GTP-binding proteins. Trends Biochem. Sci. 15: 430-434.

Smith, H.E. and A.P. Mitchell. 1989. A transcriptional cascade governs entry into meiosis in Saccharomyces cerevisiae. Mol. Cell. Biol. 9: 2142-2152.

Tanaka, K., K. M atsumoto, and A. Toh-e. 1988. Dual regulation of the expression of the polyubiquitin gene by cyclic AMP 
and heat shock in yeast. EMBO J. 7: 495-502.

Tatchell, K. 1986. RAS genes and growth control in Saccharomyces cerevisiae. J. Bacteriol. 166: 364-367.

Thevelein, J.M. 1994. Signal transduction in yeast. Yeast 10: $1753-1790$.

- - 1996. Regulation of trehalose metabolism and its relevance to cell growth and function. In The Mycota III. Biochemistry and molecular biology (ed. R. Brambl and G.A. M arzluf), pp. 395-420. Springer-Verlag, Berlin, Germany.

Thevelein, J.M. and S. Hohmann. 1995. Trehalose synthase: Guard to the gate of glycolysis in yeast? Trends Biochem. Sci. 20: 3-10.

Thompson-Jaeger, S., J. François, J.P. Gaughran, and K. T atchell. 1991. Del etion of SNF1 affects the nutrient response of yeast and resembles mutations which activate the adenylate cyclase pathway. Genetics 129: 697-706.

Toda, T., I. Uno, T. Ishikawa, S. Powers, T. Kataoka, D. Brock, S. Cameron, J. Broach, K. M atsumoto, and M. Wigler. 1985. In yeast, RAS proteins are controlling el ements of adenylate cyclase. Cell 40: 27-36.

Toda, T., S. Cameron, P. Sass, M. Zoller, J.D. Scott, B. McMullen, M. Hurwitz, E.G. Krebs, and M. Wigler. 1987. Cloning and characterization of $\mathrm{BCY} 1$, a locus encoding a regulatory subunit of the cyclic AMP dependent protein kinase in Saccharomyces cerevisiae. Mol. Cell. Biol. 7: 1371-1377.

Toda, T., S. Cameron, P. Sass, and M. Wigler. 1988. SCH9, a gene of Saccharomyces cerevisiae that encodes a protein distinct from, but functionally and structurally related to, CAM P-dependent protein kinase catalytic subunits. Genes \& Dev. 2: 517-527.

Vandercammen, A., J. François, and H.-G. Hers. 1989. Characterization of trehal ose-6-phosphate synthase and trehal ose6-phosphate phosphatase of Saccharomyces cerevisiae. Eur. J. Biochem. 182: 613-620.

Varela, J.C.S., U.M. Praekelt, P.A. M eacock, R.J. Planta, and W.H. Mager. 1995. The Saccharomyces cerevisiae HSP12 gene is activated by the high-osmolarity glycerol pathway and negatively regulated by protein kinase A. Mol. Cell. Biol. 15: 6232-6245.

Vicente-Soler, J., J.C. A rgüelles, and M . Gacto. 1991. Proteolytic activation of $\alpha, \alpha$-trehal ose-6-phosphate synthase from Candida utilis. Microbiol. Lett. 82: 157-162.

Vidan, S. and A.P. Mitchell. 1997. Stimulation of yeast meiotic gene expression by the glucose-repressible protein kinase Rim15p. Mol. Cell. Biol. 17: 2688-2697.

Vuorio, O.E., N. Kalkkinen, and J. Londesborough. 1993. Cloning of two related genes encoding the $56-\mathrm{kDa}$ and $123-\mathrm{kDa}$ subunits of trehal ose synthase from the yeast Saccharomyces cerevisiae. Eur. J. Biochem. 216: 849-861.

Wach, A., A. Brachat, R. Pöhlmann, and P. Philippsen. 1994. $\mathrm{N}$ ew heterologous modules for classical or PCR-based gene disruptions in Saccharomyces cerevisiae. Yeast 10: 17931808.

Werner-Washburne, M., J. Becker, J. Kosic-Smithers, and E.A. Craig. 1989. Y east Hsp70 RN A levels vary in response to the physiological status of the cell. J. Bacteriol. 171: 2680-2688.

Werner-Washburne, M., E. Braun, G.C. Johnston, and R.A. Singer. 1993. Stationary phase in the yeast Saccharomyces cerevisiae. Microbiol. Rev. 57: 383-401.

Woods, A., M.R. M unday, J. Scott, X. Yang, M. Carlson, and D. Carling. 1994. Yeast SNF1 is functionally related to mammalian AM P-activated protein kinase and regulates acetylCoA carboxylase in vivo. J. Biol. Chem. 269: 19509-19515.

Zervos, A.S., J. Gyuris, and R. Brent. 1993. Mxi1, a protein that specifically interacts with $\mathrm{M}$ ax to bind Myc-Max recognition sites. Cell 72: 223-232. 


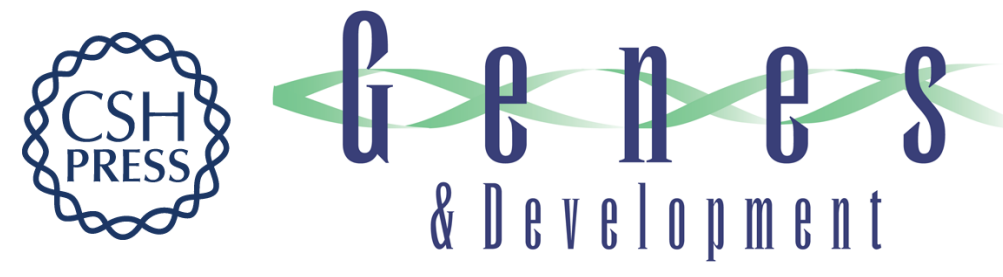

\section{Saccharomyces cerevisiae cAMP-dependent protein kinase controls entry into stationary phase through the Rim15p protein kinase}

Anke Reinders, Niels Bürckert, Thomas Boller, et al.

Genes Dev. 1998, 12:

Access the most recent version at doi:10.1101/gad.12.18.2943

References

This article cites 60 articles, 23 of which can be accessed free at:

http://genesdev.cshlp.org/content/12/18/2943.full.html\#ref-list-1

License

Email Alerting

Receive free email alerts when new articles cite this article - sign up in the box at the top

Service right corner of the article or click here.

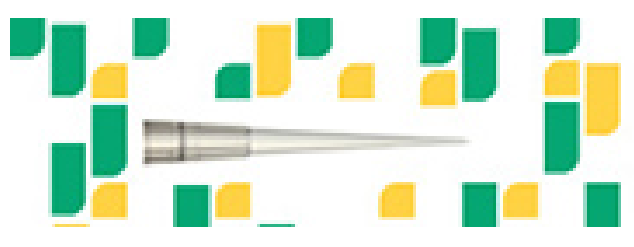

Focused on your science. 